CZASOPISMO INŻYNIERII LĄDOWEJ, ŚRODOWISKA I ARCHITEKTURY JOURNAL OF CIVIL ENGINEERING, ENVIRONMENT AND ARCHITECTURE

JCEEA, t. XXXIII, z. 63 (4/16), październik-grudzień 2016, s. 597-605

\author{
Wojciech TERLIKOWSKI ${ }^{1}$ \\ Martyna GREGORIOU-SZCZEPANIAK ${ }^{2}$ \\ Ewa SOBCZYŃSKA ${ }^{3}$ \\ Kacper WASILEWSKI ${ }^{4}$
}

\title{
DOKUMENTACJA SZCZEGÓŁOWA ZABYTKÓW STAROŻYTNYCH NA PRZYKŁADZIE OCENY STANU TECHNICZNEGO RZYMSKICH ZABUDOWAŃ W ALEKSANDRII
}

\begin{abstract}
Artykuł ukazuje specyfikę oraz wymagania dotyczące szczegółowej dokumentacji badań starożytnych zabytków architektonicznych będących częścią stanowisk archeologicznych. Dokładna i usystematyzowana dokumentacja jest cennym źródłem informacji dla przyszłych badaczy danej budowli. Metody przygotowania dokumentacji rozwijały się na przestrzeni lat: od metody klasycznej - ręczne sporządzania rzutów, przekrojów oraz rysunków szczegółowych, przez wykorzystanie fotogrametrii, a obecnie skaning laserowy. Zastosowanie tej ostatniej metody zostało przedstawione w poniższej pracy w oparciu o dokumentację rzymskich zabudowań w Aleksandrii. Konstrukcje te, to zespół korytarzy tworzących ortogonalną siatkę. Korytarze przekryte są sklepieniem beczkowym, które w miejscu ich krzyżowania tworzy sklepienie krzyżowe. Głównym materiałem konstrukcyjnym są ciosy wapienne. Stan zachowania konstrukcji jest zróżnicowany, niektóre fragmenty sklepień są zrujnowane, uszkodzone lub popękane. Diagnostyka tego typu konstrukcji wymaga wykonania dokładnej inwentaryzacji, do której wykorzystano skaning laserowy. W początkowej fazie prac zajęto się analizą chmury punktów uzyskanej w wyniku skanowania obiektu z kilku stanowisk. Dane poddano obróbce w celu wydzielenia niezbędnych przekrojów i rzutów konstrukcji. Uzyskane obrazy posłużyły jako baza do odwzorowania pierwotnego kształtu konstrukcji korytarzowych, a szczególnie jej najbardziej uszkodzonej części sklepienia krzyżowego. Umożliwiły one również określenie grubości konstrukcji, jak również spoczywającej na niej warstwie drobnych kamieni na zaprawie, a ostatecznie wykonanie modelu numerycznego w programie Abaqus, który będzie podstawą do dalszej analizy.
\end{abstract}

Słowa kluczowe: archeologiczne zabytki architektoniczne, konstrukcje murowe, skaning laserowy, sklepienia krzyżowe

\footnotetext{
1 Autor do korespondencji / corresponding author: Wojciech Terlikowski, Politechnika Warszawska, Zespół Budownictwa Ogólnego i Zrównoważonego Rozwoju, Al. Armii Ludowej 16, 00-637 Warszawa, tel.602630513,w.terlikowski@il.pw.edu.pl

${ }^{2}$ Martyna Gregoriou-Szczepaniak, Politechnika Warszawska

${ }^{3}$ Ewa Sobczyńska, Politechnika Warszawska

${ }^{4}$ Kacper Wasilewski, Politechnika Warszawska
} 


\section{Wstęp}

Jednym z podstawowych zagadnień związanych z konserwacją zabytków architektonicznych jest prawidłowa i kompletna dokumentacja obiektu. Szczególnie w przypadku obiektów starożytnych, które często wymagają prac odkrywkowych, istotnym jest zagadnienie standardów badań archeologicznych oraz dokumentacji wyników tych badań. Na podstawie poprawnie wykonanej dokumentacji możliwe jest przeprowadzenie identyfikacji materiałów i technologii wykonania konstrukcji, co jest podstawą do opracowania odpowiednich działań konserwatorskich [1]. Prace konserwatorskie przeprowadzane na obiektach, będących częścią wykopalisk archeologicznych najczęściej mają na celu przygotowanie konstrukcji do ekspozycji jako element parku archeologicznego w stanie trwałej ruiny, co dodatkowo wpływa na ich specyfikę [2][3].

\section{Metody dokumentacji szczegółowej zabytków}

W Polsce, zgodnie z Rozporządzeniem Ministra Kultury z dnia 9 czerwca 2004 r. $w$ sprawie prowadzenia prac konserwatorskich, restauratorskich, robót budowlanych, badań konserwatorskich $i$ architektonicznych, a także innych dziatań przy zabytku wpisanym do rejestru zabytków oraz badań architektonicznych i poszukiwań ukrytych lub porzuconych zabytków ruchomych wraz załącznikami, wojewódzki konserwator zabytków w pozwoleniu na przeprowadzenie badań archeologicznych określa m.in. jaka dokumentacja musi zostać sporządzona w trakcie i po badaniach. Do najważniejszych elementów tej dokumentacji należą: plan sytuacyjno-wysokościowy zabytku archeologicznego, dokumentacja przebiegu badań, inwentaryzacja polowa zabytku, sprawozdanie $\mathrm{z}$ badań zgodne z ogólnopolską bazą danych o zabytkach archeologicznych (zawierające kartę stanowiska, kopię inwentarzy, mapę lokalizacji stanowiska w skali 1:10000, plan warstwicowy stanowiska w skali min 1:1000, rozplanowanie jednostek stratygraficznych w skali min 1:200, wykazy obiektów, charakterystykę faz zasiedlenia, dokumentację fotograficzną wybraną, wnioski i zalecenia konserwatorskie), opracowanie sposobu postępowania z zabytkiem po zakończeniu badań, a w przypadku zabytków ruchomych, miejsce jego przechowywania, opracowanie wyników badań (oprócz uzupełnionych o dodatkowe informację map i materiałów występujących wcześniej w sprawozdaniu z badań, powinno zawierać wyniki ekspertyz przyrodniczych, fizykochemicznych i czasami historycznych, ilustracje - rysunki i fotografie oraz dane o stanowisku zarchiwizowane w ogólnopolskiej komputerowej bazie danych o zabytkach archeologicznych) a także bibliografię oraz zestawienie informacji o miejscu przechowywania dokumentacji poprzednich badań - jeżeli zabytek był już wcześniej badany [4][5].

W innych krajach np. Wielkiej Brytanii oraz Stanach Zjednoczonych wymagania dotyczące dokumentacji są zbliżone. Wymagane jest opracowanie planu badań oraz studium wcześniej przeprowadzonych prac, następnie szczegóło- 
wej dokumentacji przebiegu badań - zarówno fotograficznej, rysunkowej jak i opisowej, a w rezultacie opracowanie wniosków dotyczących konserwacji, sposobu przechowywania lub prac, które należy podjąć w celu zabezpieczenia zabytku [6][7]. Dodatkowo wytyczne zarówno w Polsce jak i zagranicą, zwracają szczególną uwagę na archiwizację wyników badań. Opracowania powinny być przechowywane na trwałych nośnikach, w kilku kopiach (materialnych i elektronicznych), które umieszczone powinny być w różnych miejscach [5][6].

Przygotowanie dokumentacji zabytku, można realizować w różny sposób. Najstarszą i najbardziej klasyczną metodą jest założenie osnowy geodezyjnej i na podstawie pomiarów geodezyjnych rysowanie mapy sytuacyjnej, rzutów, przekrojów oraz rysunków szczegółowych.

Jeżeli badany obszar jest rozległy, należy podzielić go siatką pomiarową, a poszczególne działki pomiarowe ponumerować. Równocześnie $\mathrm{z}$ tworzeniem rzutu poziomego, powinno się prowadzić pomiary wysokościowe i rysować przekroje pionowe badanych elementów. Jeżeli jest taka możliwość niweletę należy założyć w oparciu o reper stały państwowej osnowy geodezyjnej.

Nowoczesne przyrządy pomiarowe umożliwiają cyfrowy zapis danych pomierzonych punktów i ich przetworzenie za pomocą oprogramowania komputerowego, mimo to metoda klasyczna jest pracochłonna i czasochłonna, także wrażliwa na błędy ludzkie i mało dokładna, dlatego w miarę rozwoju technologicznego opracowano metodę wykonywania dokumentacji zabytków za pomocą fotogrametrii.

Początkowo polegała ona na wykonywaniu zdjęć poziomych lub ukośnych za pomocą analogowych aparatów fotograficznych. Aby uzyskać szerokie pole obrazu używano drabin, balonów, a później także samolotów i helikopterów. Fotografie dawały obraz przebiegu badań, odwzorowywały dokładnie wygląd danego obszaru czy obiektu, ale ze względu na brak skali mogły być jedynie uzupełnieniem dokumentacji rysunkowej. Rozwój techniki cyfrowej pozwolił na skanowanie zdjęć wykonanych techniką analogową a następnie przetworzenie skanów już w środowisku cyfrowym na ortofotomapy.

Obecnie, dzięki zastosowaniu nowoczesnych aparatów cyfrowych, możliwe jest stworzenie pełnej inwentaryzacji obiektu za pomocą fotogrametrii. W przypadku obiektów przestrzennych, jakimi zwykle są budowle zabytkowe, należy posłużyć się fotogrametrią dwuobrazową. W tej metodzie podstawą do opracowani wyników są pary zdjęć pomiarowych, stereoskopowych. Przed wykonaniem tych zdjęć konieczne jest złożenie osnowy geodezyjnej i fotogrametrycznej składającej się z punktów o znanych, pomierzonych współrzędnych rzeczywistych, które znajdują się później na zdjęciach. Punkty te pozwalają na stworzenie w środowisku cyfrowym wektorowych planów, rzutów oraz przekrojów budowli o określonej skali.

Dostępne oprogramowanie, oprócz płaskich rysunków wektorowych, umożliwia również tworzenie modeli trójwymiarowych poprzez łączenie wykonanych zdjęć i ich obróbkę cyfrową. 
Metoda fotogrametryczna jest szybsza i dokładniejsza od metody klasycznej. Pozwala na tworzenie cyfrowych obrazów wektorowych i rastrowych o dużej dokładności. Obrazy te w postaci map, rysunków lub barwnych modeli mogą być drukowane lub wykorzystywane do dalszych prac w środowisku komputerowym, co znacznie upraszcza sposób ich archiwizacji oraz stwarza szersze możliwości wykorzystania takiej dokumentacji niż w metodzie klasycznej [8] [9].

Obecnie coraz powszechniej wykorzystywany w diagnostyce konstrukcji, zwłaszcza zabytkowych jest naziemny skaning laserowy (TLS - Terrestrial Laser scanning). Zagadnienie to zostało opracowane w dostępnej literaturze m.in. [11], [12], [13], [14], [15], [16]. Jego działanie polega na pomiarze odległości oraz kąta pomiędzy urządzeniem a badanym obiektem, co pozwala na wyznaczenie zbioru współrzędnych X, Y,Z tworzących tzw. chmurę punktów. Reprezentują one powierzchnię skanowanego elementu, od którego odbija się wiązka promieniowania wysyłanego przez laser. Zwykle zachodzi konieczność, tak jak ma to miejsce w przypadku omawianych tu konstrukcji korytarzowych, wykonywania pomiaru z kilku stanowisk i następnie łączenia wykonywanych pomiarów. Daje to, tak jak w naszym przypadku zwiększoną dokładność pomiarów nawet do $1 \mathrm{~mm}$. Specjalistyczne oprogramowanie wykorzystywane do przetwarzania chmury punktów pozwala na obróbkę wyników, wykonanie interesujących nas przekrojów a ostatecznie dokonania bezpośrednich pomiarów. Zastosowanie skaningu laserowego przedstawiono dokładnie w dalszej części artykułu [10].

\section{Antyczne konstrukcje murowe w Aleksandrii w Egipcie}

Szczegółowa dokumentacja konstrukcji zabytkowych ma bardzo duże znaczenie przy diagnozowaniu konstrukcji starożytnych, w których wszystkie badania należy wykonać ,in situ”. Widać to bardzo wyraźnie na przykładzie badań prowadzonych w późno antycznych (z IV w. n.e.) budowlach podziemnych, znajdujących się na wykopaliskach na Kom-el-Dikka w Aleksandrii, w Egipcie. Długoletnie badania archeologiczne są prowadzone pod kierunkiem dr Grzegorza Majcherka z Centrum Archeologii Śródziemnomorskiej Uniwersytetu Warszawskiego. Znajdują się tu ruiny zabudowań tworzących Uniwersytet Aleksandryjski, a także obiekty wcześniejsze. Przedmiotem badań diagnostycznych były, zachowane do dzisiaj, podziemne obiekty budowlane, będące zespołem podziemnych korytarzy, tworzących ortogonalną siatkę. Funkcja tych obiektów nie jest do końca jasna. Wykonane są one z ciosów wapiennych w kształcie klińców, przekrytych sklepieniem beczkowym. W miejscach krzyżowania się korytarzy, sklepienie beczkowe przechodzi w sklepienie krzyżowe. Jest to układ wyjątkowy i oryginalny, niestosowany powszechnie w późnym antyku, niemający odniesienia do żadnych zachowanych konstrukcji. Stan techniczny tych konstrukcji oraz stopień zachowania jest zróżnicowany. Na dużym obszarze korytarze zostały zniszczone poprzez wybudowanie na nich, w późniejszym okresie, zabudowania łaźni rzymskiej. Fragmenty sklepień są zrujnowane, uszkodzone 
i popękane. Widać wyraźne wyboczenia krzywizny łuków i miejscowe, nadmierne ugięcia. Diagnostyka tych konstrukcji, mająca na celu opracowanie programu ich zabezpieczenia, wzmocnienia i rekonstrukcji, wymagała bardzo dokładnej inwentaryzacji i analizy układu poszczególnych elementów murowych.

W pierwszej fazie wykonane zostały oględziny konstrukcji i badania makroskopowe, sporządzona została dokumentacja fotograficzna, uwzględniająca inwentaryzację największych uszkodzeń. Szerokość rys występujących w konstrukcji jest również bardzo zróżnicowana i waha się od kilku milimetrów do ponad jednego centymetra, w zależności od usytuowania. Miejscami konstrukcje są zniszczone mechanicznie, a także zdegradowane biologicznie, widoczne są wykwity soli i destrukcja granularna elementów.

Przyczyną postępującej degradacji biologicznej konstrukcji jest zawilgocenie, powodujące lokalnie silne wysolenia powierzchniowe i rozwarstwienia struktury kamieni. Ze względu na złożony kształt konstrukcji, w obszarach przenikania wzajemnie prostopadłych sklepień beczkowych, konieczna była dokładna analiza kształtu sklepienia, obszarów poszczególnych pól sklepiennych (tzw. wysklepków), ścian i elementów murowych. Zastosowano do tego skaning laserowy 3d. Otrzymane wyniki, wraz z badaniami laboratoryjnymi określającymi parametry fizyczne i wytrzymałościowe elementów murowych i zaprawy, dają możliwość dokładnego przygotowania programu zabezpieczającego, konserwatorskiego i rekonstrukcji antycznych budowli podziemnych.

\section{Diagnostyka laserowa konstrukcji korytarzowych w Aleksandrii w Egipcie}

Na podstawie skaningu laserowego przeprowadzonych w czerwcu 2015 roku podjęto próbę odwozorania pierwotnego kształtu konstrukcji korytarzowych. Częścią, która wzbudzała największe zainteresowanie było najbardziej zniszczone skrzyżowanie dwóch korytarzy - Rys. 1 fragment a oraz Rys. 2.

Na Rys. 2 wyraźnie widać uszkodzenie sklepienia krzyżowego w analizowanym segmencie. Ubytek fragmentu sklepienia obejmuje swoim zakresem także miejsca przenikania się sklepień łukowych. Może to stanowić zagrożenie dla stabilności układu.

Jako odwzorowanie pierwotnej konstrukcji, na podstawie przekrojów otrzymanych ze skaningu laserowego możliwe było dopasowanie wycinka łuku kłowego o promieniu 1,65 m i strzałce 1,5 m (Rys. 3). Jak widać na przekrojach ten kształt sklepień jest zgodny z prawdopodobnym kształtem pierwotnym, natomiast wyraźnie widać odkształcenia sklepienia korytarza głównego o wartości od $0,2 \mathrm{~m}$ do $0,4 \mathrm{~m}$. Może to świadczyć o prawdopodobnym przeciążeniu sklepienia, które mogło mieć miejsce w historii obiektu. Zdecydowanie większe odkształcenie krawędzi otworu jest prawdopodobnie skutkiem zarwania się sklepienia, przez co istniejąca część straciła podparcie.

Na podstawie przekroju z Rys. 3A można także ustalić grubości poszczególnych warstw sklepienia. Główna część konstrukcyjna wykonana z bloków 


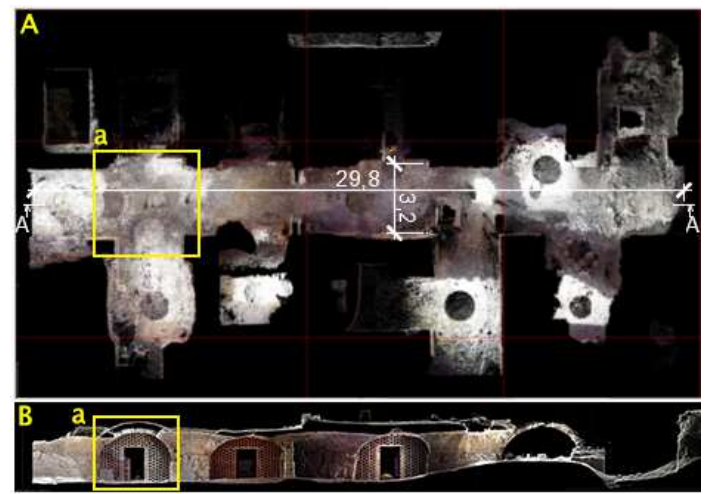

Rys. 1. Obrazy ze skaningu laserowego: rzut (A) i przekrój podłużny A-A (B) konstrukcji korytarzowych w Aleksandrii; a - analizowany segment

Fig. 1. Laser scanning images: horizontal projection (A) and longitudinal section A-A (B) of corridor structures in Alexandria; a - analysed segment
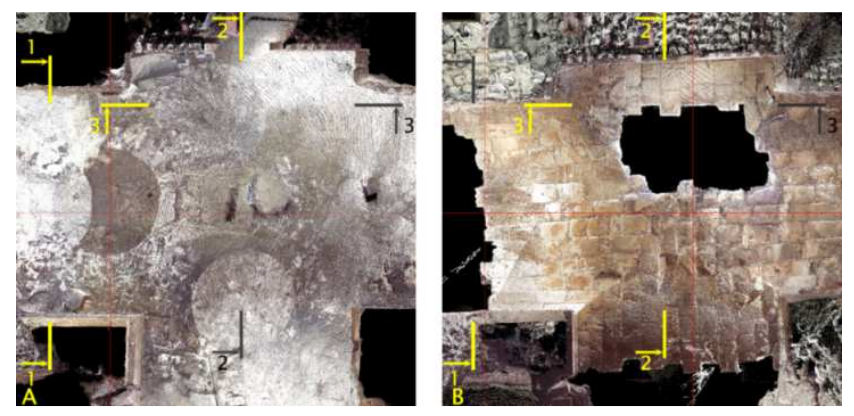

Rys. 2. Obrazy ze skaningu laserowego: rzut (A) i widok od dołu na sklepienie (B) analizowanego fragmentu oznaczonego na Rys. 1 wraz z oznaczonymi przekrojami

Fig. 2. Laser scanning images: horizontal projection (A) and view of the vaults from below (B) of the analysed segment marked on Fig. 1 with specified cross-sections
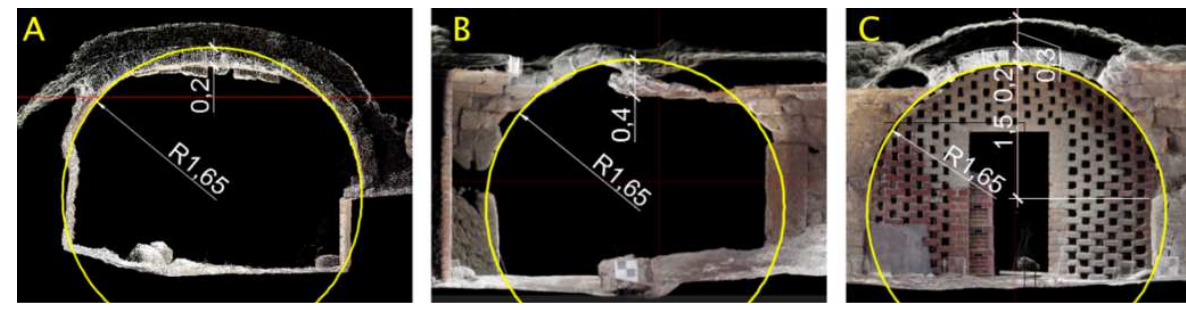

Rys. 3. Obrazy ze skaningu laserowego: przekrój 1-1 (A), przekrój 2-2 (B); przekrój 3-3 (C) zgodnie z oznaczeniami z Rys. 2

Fig. 3. Laser scanning images: cross-section 1-1 (A); cross-section 2-2 (B); crosssection 3-3 (C) based on marking from Fig. 2 
kamiennych ma grubość ok. 0,2 m, natomiast warstwa zewnętrzna $\mathrm{z}$ drobniejszych kamieni na zaprawie ma grubość ok. $0,3 \mathrm{~m}$.

Wykorzystując powyższe pomiary i założenia możliwe było stworzenie numerycznego modelu w celu przeprowadzenia analizy MES z wykorzystaniem programu Abaqus. Tego typu analiza może być wykorzystana między innymi do potwierdzenia hipotezy o nadmiernych odkształceniach sklepienia $\mathrm{w}$ wyniku jego przeciążenia. Jednak w celu zapewnienia wiarygodności wyników konieczne jest przeprowadzeni badań materiałowych umożliwiających ustalenie właściwości wytrzymałościowych muru, a w szczególności ich charakter w zakresie nieliniowym analizy.

\section{Wnioski}

Diagnostyka starożytnych obiektów zabytkowych wymaga dokładnej inwentaryzacji konstrukcji wraz z identyfikacją ustroju nośnego. Szczególnie istotne jest stworzenie dokładnej inwentaryzacji rys, uszkodzeń i odkształceń elementów tworzących ustrój nośny. Specyfiką obiektów starożytnych, będących częścią wykopalisk archeologicznych, jest okresowy dostęp i możliwość prowadzenia badań i pomiarów, co utrudnia to weryfikować wyniki wcześniej pozyskanych pomiarów i badań. W tego typu przypadkach koniecznie jest wykonanie dokumentacji, która będzie możliwa do zweryfikowania bez dostępu do badanego obiektu. Wyjątkowo przydatnym narzędziem do tego typu zadań staje się, coraz częściej, skaning laserowy, który umożliwia szczegółową analizę kształtu badanych obiektów budowlanych oraz pomiary odkształceń i uszkodzeń sprzed ekranu monitora. Wyniki skaningu laserowego dają również podstawę do szybkiego i bardzo dokładnego sporządzenia modeli numerycznych, które mogą być podstawą dalszych analiz statyczno-wytrzymałościowych.

\section{Literatura}

[1] Terlikowski, W. R.: Aspekty techniczne i inżynierskie konserwacji starożytnych konstrukcji murowych jako trwałej ruiny. Materiały Budowlane, (11), 2013, s. 116-118.

[2] Terlikowski, W. R.: Identyfikacja materiałów i technologii wykonania historycznych konstrukcji murowych w procesie ich konserwacji i rehabilitacji. Materiały Budowlane, (11), 2015, s. 166-169.

[3] Terlikowski, W. R., Wasilewski, K.: Ekspozycja zabytkowych obiektów architektury antycznej na podstawie własnych przykładów. Czasopismo Inżynierii Lądowej, Środowiska i Architektury - Journal of Civil Engineering, Environment and Architecture, JCEEA, t. XXXII, z. 62 (2/15), 2014, s. 533-544, DOI:10.7862/rb.2015.82.

[4] Dz.U. 2004 nr 150 poz. 1579 Rozporządzenie Ministra Kultury z dnia 9 czerwca 2004 r. w sprawie prowadzenia prac konserwatorskich, restauratorskich, robót budowlanych, badań konserwatorskich i architektonicznych, a także innych działań przy zabytku wpisanym do rejestru zabytków oraz badań architektonicznych i poszukiwań ukrytych lub porzuconych zabytków ruchomych. 
[5] Krajowy Ośrodek Badań i Dokumentacji Zabytków, Standardy metodyczne i dokumentacyjne badań archeologicznych i opracowań ich wyników 2006.

[6] The Chartered Institute for Archaeologists is incorporated by Royal Charter, Standard and guidance for the collection, documentation, conservation and research of archeological materials 2014.

[7] Idaho State Historic Preservation Office and Archaeological Survey of Idaho, Guidelines for documenting archaeological and historical surveys.

[8] Boroń A., Rzonca A., Wróbel A.: Metody fotogrametrii cyfrowej i skanowania laserowego w inwentaryzacji zabytków. Roczniki Geomatyki 2007, Tom V, Zeszyt 8.

[9] Boroń A., Borowiec M., Wróbel A.: Rozwój cyfrowej technologii inwentaryzacji obiektów zabytkowych na przykładzie doświadczeń zakładu fotogrametrii i informatyki teledetekcyjnej AGH. Archiwum Fotogrametrii, Kartografii i Teledetekcji, Vol. 19, 2009.

[10] https://www.igipz.pan.pl/zsigik-projekty-tls-wprowadzenie.html \{dostęp 02.05.2016\}.

[11] Kościuk J.: 3D scanning and modeling of the upper terrace of the Hatshepsut Temple in Deir el-Bahari as an example of architectural heritage documentation for restoration purposes (Skanowanie i modelowanie 3d górnego tarasu świątyni Hatszepsut w Deir el-Bahari jako przykład dokumentacji dla celów konserwatorskich). Wiadomości Konserwatorskie 26, 2009, s. 705-17.

[12] Brykowska M., Metody pomiarów i badań zabytków architektury. Oficyna Wydawnicza Politechniki Warszawskiej, Warszawa 2003.

[13] Pesci A., Bonali E., Galli C., Boschi E.: Laser scanning and digital imaging for the investigation of an ancient building: Palazzo d'Accursio study case (Bologna, Italy). Journal of Cultural Heritage 13, 2012, s. 215-220.

[14] Murphy M., McGovern E., Olwill R., Pavia S.: Identification of historic methods of construction using digital photogrammetry and laser scanning, in: S. Dequal (Ed.), Proceedings of CIPA, XX Symposium, Torino, Italy, September 26-01 October, 2005.

[15] Gołembnik A.: Rola nowych technik dokumentacyjno-pomiarowych w interdyscyplinarnych działaniach badawczo-konserwatorskich, Wiadomości Konserwatorskie Journal of Heritage Conservation, 2014, $\mathrm{Nr}$ 40, s: 83-93.

[16] Gładki M., Czajkowski K., Gołembnik A., Kadłuczka A., Morysiński T., Rulewicz J.: Zastosowane cyfrowych technik dokumentacyjnych przy badaniu zespołów zabytkowych jako proces interdyscyplinarny - zintegrowana dokumentacja, cele, możliwości, praktyka, [w:] Kongres Konserwatorów Zabytków, red. J. Jasieńko, Dolnośląskie Wydawnictwo Edukacyjne, Warszawa, s. 91-99.

\section{DETAILED DOCUMENTATION OF ANCIENT MONUMENTS: CASE STUDY OF ROMAN STRUCTURES IN ALEXANDRIA}

\section{S u m m a r y}

The article shows the specificity and requirements for detailed documentation of researches on ancient architectural monuments that are part of the archaeological sites. Detailed and systematized documentation is a valuable source of information for future researchers of this structure. 
Methods of preparation of documentation developed over the years: from the classical method manual preparation of plans, sections and detailed drawings, through the use of photogrammetry and now laser scanning. The use of the last method is presented in this paper basing on the documentation of Roman buildings in Alexandria. These structures are corridors creating an orthogonal grid. The corridors are covered with barrel vaults, which at the point of crossing creates a cross vault. The main construction material are limestone blocks. The condition of the structure is diversified, some parts of the vaults are ruined, damaged or cracked. Diagnosis of this type of structure requires a thorough inventory, in which laser scanning was used. In the initial phase of work the analysis of the cloud of points obtained by scanning the object from several positions was carried out. The data were processed to isolate the necessary sections and plans of structure. The resulting images were used as the basis for mapping the original shape of corridors, and especially its most damaged part of the cross vault. It has also allowed to determine the thickness of the structure, as well the layer of tiny stones laying on it, and finally performing numerical model in Abaqus, which will be the basis for further analysis.

Keywords: archaeological architectural monuments, masonry structures, laser scanning, groin vaults

DOI:10.7862/rb.2016.304

Przestano do redakcji: 08.12.2016 $r$.

Przyjęto do druku: 20.12.2016 $r$. 
